\title{
Default neglect in attempts at social influence
}

\author{
Julian J. Zlatev ${ }^{a, 1}$, David P. Daniels ${ }^{b}$, Hajin Kimc, and Margaret A. Neale

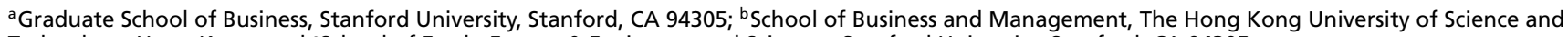 \\ Technology, Hong Kong; and 'School of Earth, Energy \& Environmental Sciences, Stanford University, Stanford, CA 94305
}

Edited by Susan T. Fiske, Princeton University, Princeton, NJ, and approved September 29, 2017 (received for review July 20, 2017)

\begin{abstract}
Current theories suggest that people understand how to exploit common biases to influence others. However, these predictions have received little empirical attention. We consider a widely studied bias with special policy relevance: the default effect, which is the tendency to choose whichever option is the status quo. We asked participants (including managers, law/business/medical students, and US adults) to nudge others toward selecting a target option by choosing whether to present that target option as the default. In contrast to theoretical predictions, we find that people often fail to understand and/or use defaults to influence others, i.e., they show "default neglect." First, in one-shot defaultsetting games, we find that only $\mathbf{5 0 . 8 \%}$ of participants set the target option as the default across 11 samples $(n=2,844)$, consistent with people not systematically using defaults at all. Second, when participants have multiple opportunities for experience and feedback, they still do not systematically use defaults. Third, we investigate beliefs related to the default effect. People seem to anticipate some mechanisms that drive default effects, yet most people do not believe in the default effect on average, even in cases where they do use defaults. We discuss implications of default neglect for decision making, social influence, and evidence-based policy.
\end{abstract}

decision making | social influence | default effect | nudges

choice architecture

D efault options can have an enormous impact on important health, financial, and environmental outcomes. Currently, in the United States, there is a severe undersupply of organ donors, and over 8,000 people die while waiting for an organ donation every year. Yet enrolling people as organ donors by default could lead to donation rates 40 percentage points higher than they are now (1), preventing thousands of deaths. Most Americans are saving far too little money for retirement (2), and millions of people have saved nothing at all (3). Yet companies that enroll employees in a retirement savings plan by default can increase savings rates by 50 percentage points (4), vastly improving quality of life among the elderly. Across the world, environmental protection is a critical, but underprovided, public good (5). Yet regions in which green energy options are the default have rates of energy-efficient utility use that are 90 percentage points higher (6), promoting environmentally friendly behaviors.

A vast and growing body of research has demonstrated that people tend to choose whichever option is set as the default [known as the default effect or status quo bias (7-11)]. As evidenced above, setting wise defaults can help save lives, money, and the environment, often on a large scale and at little cost (1, $8,12,13)$. Accordingly, among academics, policy makers, and organizations, there has been a surge of interest in behavioral interventions and social influence tactics (including defaults) that "nudge" people to make better choices $(8,14-18)$.

However, a puzzle remains: Despite evidence of the power of defaults, they remain underutilized. For example, randomized clinical trials demonstrate that having healthcare professionals provide HIV screenings by default could help a large portion of the $\sim 150,000$ Americans who are HIV-positive but remain undiagnosed $(19,20)$. In 2006, the US Centers for Disease Control and Prevention recommended application of such a default, and the World Health Organization followed with a similar recommendation in 2007. Yet, as of 2016, most hospitals had not implemented these policy recommendations and did not provide HIV screenings by default (19). This simple change could save thousands of lives, including the lives of many members of tradition- ally stigmatized groups (21); why then have healthcare professionals failed to implement this simple, clear-cut policy?

Since at least the 1950s (22), researchers have sought to understand the psychological factors involved in persuasion and influence (23-26). Tactics such as the foot-in-the-door technique (27) and the norm of reciprocity (28) have been found to be simple and reliable ways to alter others' behavior. However, while a great deal is known about how people respond to influence tactics such as these, very little is known about whether and how people strategically use these tactics to influence others $(29,30)$. Moreover, virtually anyone can use influence tactics to change others' behavior, especially with tactics that are easy to implement and widely effective, such as the default effect. For example, physicians can give their patients a default when choosing a medical treatment; parents can give their children a default when deciding which bedtime book to read; and leaders can give their followers a default when selecting a goal to pursue. In all of these situations, people could present a default option strategically, anticipating that others' choices will be biased toward the status quo. However, do people actually understand default nudges enough to use them strategically (31)? Surprisingly, while the literature on social influence is vast and multidisciplinary [e.g., refs. $24,29,32$, and 33], this fundamental question has been almost completely overlooked.

On the one hand, several important theoretical perspectives predict that people should be aware of systematic decision biases in others and thus adept at exploiting those biases to influence them. Current economic models of people who strategically use nudges assume that they have rational expectations; thus, they will hold correct beliefs about others' biases and will therefore be able to optimally harness them to influence others in desired directions (34). Several researchers in psychology have made complementary arguments, proposing that "people recognize the existence, and the impact, of most of the biases that social and cognitive psychologists have described over the

\section{Significance}

While a great deal is known about how people respond to influence tactics that are used on them, almost nothing is known about whether people understand these tactics and strategically use them to influence others. We examine whether people are successful at using the default effect, a widely studied bias with special policy relevance, to influence others' choices. Overall, we find that managers, law/business/medical students, and US adults often fail to understand and/or use defaults, with some interesting exceptions. These findings suggest that the scope for improving social welfare via behavioral policy interventions is vast.

Author contributions: J.J.Z. and D.P.D. designed research; J.J.Z. and D.P.D. performed research; J.J.Z. and D.P.D. analyzed data; and J.J.Z., D.P.D., H.K., and M.A.N. wrote the paper.

The authors declare no conflict of interest.

This article is a PNAS Direct Submission.

Published under the PNAS license.

Data deposition: Data and materials are available at https://osf.io/4efdv/.

${ }^{1}$ To whom correspondence should be addressed. Email: jjzlatev@stanford.edu.

This article contains supporting information online at www.pnas.org/lookup/suppl/doi:10. 1073/pnas.1712757114/-/DCSupplemental. 
past few decades" [ref. 35, p. 369] as a result of observational or instructional learning. Further, one review of the literature on social influence suggests that "influence agents" commonly succeed when trying to influence "targets" in desired directions (24). Even if people do not fully anticipate the magnitudes of others' biases, they could still anticipate the directions of these biases $(36,37)$, which is often sufficient for using nudges optimally (8). Consistent with this possibility, one recent study suggests that people think others are influenced toward national-level defaults when deciding whether or not to be an organ donor, even though people underestimate the magnitude of this default effect (36). In summary, current economic models of people who use nudges and related perspectives in psychology suggest that people should be good at understanding and/or using defaults in a sophisticated way, suggesting the following three hypotheses.

Hypothesis 1: People should be good at using defaults to influence others in desired directions (i.e., the rate of using optimal defaults should be better than chance).

Hypothesis 2: People should hold correct beliefs about what defaults do (i.e., the rate of holding correct beliefs about the direction of the default effect should be better than chance).

Hypothesis 3: People who hold correct beliefs about the direction of the default effect should be better at using defaults to influence others in desired directions.

On the other hand, people might hold incorrect beliefs about others' systematic decision biases-perhaps stemming from idiosyncratically erroneous (39) or systematically biased (40) lay theories about what factors influence others' behavior. ${ }^{*}$ As a result, people might be unable to optimally harness these biases to influence others in desired directions. While, in principle, people could adjust their incorrect beliefs by learning from past experiences (41), in practice, effective learning typically requires immediate and accurate feedback, which is unlikely to be available in most real-world environments (42). Even with immediate and accurate feedback, however, additional opportunities for learning can still fail to improve patterns of suboptimal decision making $(43,44)$. In noisy environments, learning about systematic causal relationships-such as the default effect-is hard (45), despite its importance for good decision making in interactive situations $(43,46,47)$. Consistent with this view, Johnson and Goldstein (48) conjecture that people may hold incorrect beliefs about the default effect. In summary, it is possible that people may show "default neglect" (48)-i.e., they may fail to understand and/or use defaults to effectively influence others, which would be inconsistent with some or all of hypotheses 1 to 3 .

In addition to considering the aforementioned theoretical predictions, we also asked experts in the field of judgment and decision making to predict whether people would be good at using the default effect to influence others. Interestingly, the predictions of these experts were in line with the predictions of current economic models of people who use nudges. In an email survey of members of the Society for Judgment and Decision Making $(n=$ 133), the overwhelming majority of experts-90.1\% - predicted that people would successfully use defaults to influence others in desired directions. Only $2.3 \%$ of experts predicted that people would fail to use defaults altogether. These predictions may help explain the dearth of existing research on default neglect.

To experimentally investigate whether people are able to strategically use default nudges, we developed a "default game" involving two players, inspired by similar interpersonal and intrapersonal influence games used in previous research [e.g., refs. 49-51]. In the default game, player 1 is a "Choice Archi-

* By incorrect belief, we mean either (i) believing that there is no default effect, (ii) believing that there is an antidefault effect, or (iii) having no belief about the default effect but making decisions as if holding one of the two aforementioned incorrect beliefs [e.g., a CA who has no beliefs about the default effect might set defaults randomly, perhaps appealing to the principle of insufficient reason (38)]. In this paper, we do not focus on the third type of incorrect belief mentioned here. tect" (CA) who decides which of two options to present as the default option to player 2 (8). Player 2 is a "Choice Maker" (CM) who chooses an option. The CA's objective is to select a default option that will influence the CM toward choosing a randomly assigned target option. If the CM does choose the target option, the CA may receive a monetary bonus (of up to $\$ 4$ ). CAs who decide to present the target option to CMs as the default option are considered to have made the "optimal" CA decision. ${ }^{\dagger}$

All experiments were approved by Stanford University's Institutional Review Board, and all participants gave informed consent.

\section{Studies 1a to 1k: Do People Use Defaults in One-Shot Games?}

Materials and Methods. Using the default game, we asked 11 samples of participants (total $n=2,844$ ) to influence others toward selecting a target option by choosing whether to present the target option or a nontarget option as the default. In samples 1 to 3 (studies 1a to 1c), US adults were asked to influence another person's choice of job by setting a default job (based on a vignette adapted directly from ref. 53). In samples 4 and 5 (studies $1 \mathrm{~d}$ and 1e), Stanford law (JD) students and US adults were asked to imagine they were a legislator and wanted to influence consumers' choice of insurance policy by setting a default insurance policy. In samples 6 to 8 (studies 1f to $1 \mathrm{~h}$ ), Stanford business (MBA) students, business executives, and US adults were asked to imagine they were a CEO and wanted to influence an employee's choice of job by setting a default job. In samples 9 to 11 (studies 1i to 1k), Northwestern and Stanford medical (MD) students and doctors, and US adults were asked to imagine they were on a hospital panel and wanted to influence a patient's choice of medication by setting a default medication (see Supporting Information for full instructions). Five of the CA samples (studies 1a, 1b, 1c, 1i, and 1k) made incentivized decisions involving real CMs, while the other six CA samples (studies 1d, 1e, 1f, $1 \mathrm{~g}, 1 \mathrm{~h}$, and $1 \mathrm{j}$ ) made hypothetical decisions.

Results. Across studies 1a to $1 \mathrm{k}$, we find evidence that people failed to use default nudges optimally. Results indicated an overall CA decision pattern consistent with random chance (i.e., consistent with CAs not using defaults at all), with a narrow 95\% confidence interval that included $50 \%$ (fixed effects model: $50.8 \%, 95 \%$ CI $[49.0 \%, 52.7 \%]$; random effects model: $51.9 \%$, $95 \%$ CI $[47.4 \%, 56.5 \%])$. These results were thus inconsistent with hypothesis 1 . To investigate potential heterogeneity across our studies, we split the samples into two groups; the "nonprofessional samples" included online adult studies and nonprofessional university affiliates, while the "professional samples" included executives, business students, medical students, and law students. The meta-analysis of the nonprofessional samples $(k=7, n=2,187)$ indicated an overall CA decision pattern consistent with random chance, with a $95 \%$ confidence interval that included $50 \%$ (fixed effects model: $48.3 \%, 95 \%$ CI $[46.2 \%$, $50.4 \%$ ]; random effects model: $48.4 \%, 95 \%$ CI $[44.8 \%, 52.0 \%])$. The meta-analysis of the professional samples $(k=4, n=657)$ indicated an overall CA decision pattern that was significantly better than chance, with a $95 \%$ confidence interval that did not include $50 \%$ (fixed effects model: $59.8 \%$, 95\% CI [55.9\%, 63.5\%]; random effects model: $59.0 \%, 95 \%$ CI [50.2\%, 67.3\%]). See Fig. 1 for the meta-analytic results for each group. Thus, the professionals used default nudges at a rate that was better than chance and better than that of the nonprofessional samples, although they were still closer to random chance than to optimality. Differences in CA behavior across populations could

Random assignment of the target option lets us evaluate how good people are at using defaults to influence others independent of idiosyncratic preferences regarding the individual options (see experiment 1 in ref. 52, which asked University of California, San Diego undergraduates to set a default for hypothetical others but did not randomly assign a target option). 


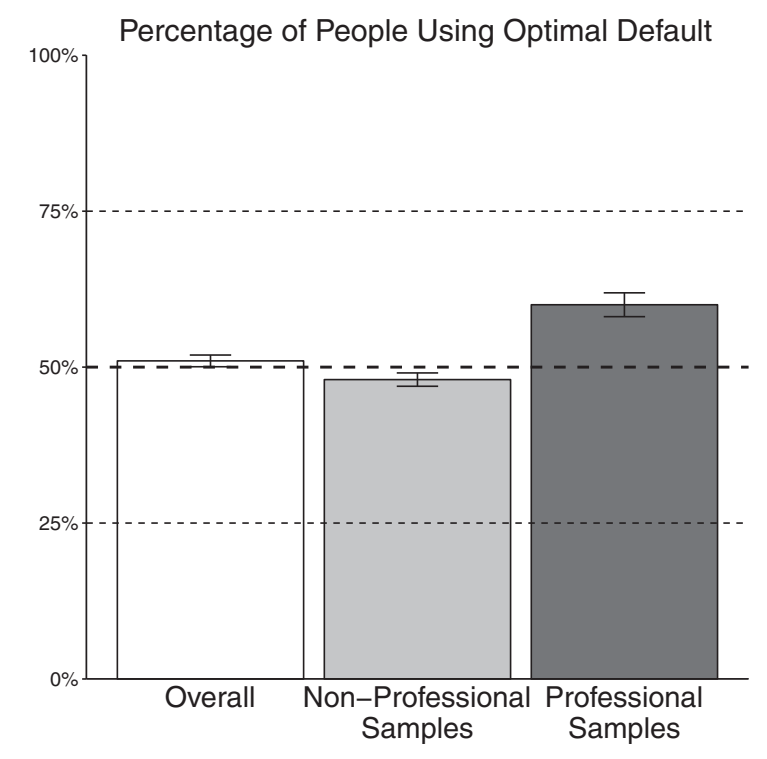

Fig. 1. Study 1: meta-analysis of percentage of CAs using optimal default nudges across all 11 studies. Error bars are SEs. The left bar shows overall results. The middle bar includes all nonprofessional samples (i.e., online adult studies and nonprofessional university affiliates). The right bar includes all professional samples (i.e., managers, JD students, MBA students, and MD students).

potentially reflect a number of factors, including differences in education, practice, or motivation.

\section{Study 2: Do People Use Defaults in a Repeated One-Shot Game?}

Studies 1a to $1 \mathrm{k}$ used "one-shot" default games in which CAs made a single decision about which default to present to a CM. To test whether the results of studies $1 \mathrm{a}$ to $1 \mathrm{k}$ are robust to experience and feedback, we ran a follow-up study in which each CA played the one-shot default game 20 times in a row, forming a 20-round "repeated one-shot" default game (54). The repeated nature of this game allowed us to test whether the default neglect we observed in CA decisions is robust to experience and feedback.

Materials and Methods. Participants played the one-shot default game from study 1a 20 times in a row. Specifically, participants acted as CAs and decided how to present a choice of two jobs to $\mathrm{CMs}$, with one job having more pay and one job having more vacation. For each CA, one of the two jobs was randomly assigned to be the target option for all 20 rounds. In each round, CAs chose which option to set as the default option. After each round, CAs were randomly matched with the real response of a $\mathrm{CM}$ who had previously made a job choice within that choice environment (i.e., the choice environment with the default that was selected by the CA); then, CAs were told whether the CM had actually chosen the target option or not. (We used the same sample of CMs to match with CAs as in study 1 . These CMs demonstrated a default treatment effect of 25.2 percentage points. That is, the CMs were 25.2 percentage points more likely to choose an option when it was the default than when it was not the default.) CAs earned a $\$ 0.25$ bonus for each round in which they were paired with a CM who chose the target option. Thus, CAs could earn up to $\$ 5$ on top of their base pay based on their decisions.

We also included seven comprehension check survey questions regarding the $\mathrm{CM}$ options, the number of rounds, and the payment structure. Participants completed these questions before making their decisions. There were no significant correlations between comprehension check outcomes and CA performance (see Supporting Information for details).
Results. Pooling across rounds 1 to 20, on average CAs used default options optimally 9.86 times (out of a maximum possible 20), which was not significantly different from random chance $(z=0.27, p=0.78)$. In fact, participants were no better than chance in any one of the 20 rounds (all $p \mathbf{s}>0.19$ ). In round 1 (the first round), 33\% of CAs used default nudges optimally, which was significantly worse than random chance $\left[\chi^{2}(1)=16.01, p<0.001\right]$. This was qualitatively similar to some of the CA decisions in study 1 . In round 20 (the final round), $54 \%$ of CAs used default nudges optimally, which was significantly better than round 1 behavior $(z=3.89, p<0.001)$ but not significantly different from random chance $\left[\chi^{2}(1)=0.81, p=0.37\right]$.

Fig. 2 shows that, as CAs repeatedly played the one-shot default game over time, the rate of optimal nudge selection first increased somewhat (suggesting a modest amount of learning) but then leveled off. Because there appeared to be a difference between one-shot games played in the first half versus the second half of the study, we post hoc split the data into rounds 1 to 10 and rounds 11 to 20 and analyzed each of these halves separately. Specifically, using ordinary least-squares (OLS) regression with robust standard errors clustered by participant, we find that, across rounds 1 to 10 , each additional round significantly increased the rate of optimal nudge selection by $1.8 \%$ $[t(149)=4.29, p<0.001]$. However, across rounds 11 to 20 , we find that each additional round no longer significantly increased the rate of optimal nudge selection $[t(149)=1.17, p=0.12]$.

Overall, whether we pool behavior across all 20 rounds or consider only behavior in round 20 , we find that default neglect in CA decisions does persist, even with experience and feedback. These results were thus inconsistent with hypothesis 1 .

\section{Study 3: Do People Hold Accurate Beliefs About the Default Effect?}

CAs failed to set optimal defaults across both studies $1 \mathrm{a}$ to $1 \mathrm{k}$ and study 2 , in opposition to the predictions of both current economic models of people who use nudges and experts in judgment and decision making. What do people (mis)believe or (mis)understand about the default effect? An investigation of people's beliefs about what defaults do, and their understanding of the mechanisms that seem to drive default effects, might be able to shed additional light on why many CAs often fail to use defaults.

We begin by investigating CAs' beliefs about the default effect, i.e., their predictions about how changing a default will change

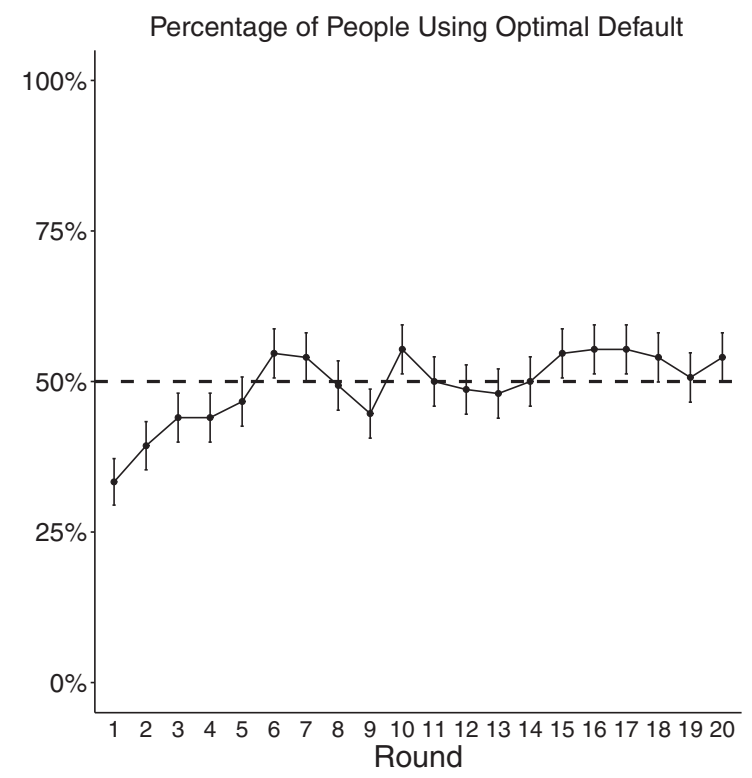

Fig. 2. Study 2: percentage of CAs using optimal default nudges in a 20round repeated one-shot default game. Error bars are SEs. 
CMs' choices. We also investigate CA beliefs related to the three most common explanations advanced in the literature for why defaults affect CM behavior (1). First, CMs might stick to defaults because of the effort costs associated with making an active decision. Switching away from a default requires cognitive (and sometimes physical) effort, and so people may stay with the default option because doing so is relatively effortless $(9,55)$. Second, CMs might stick to defaults because of loss aversion (56). Default options often represent the status quo, and the disadvantages or losses that result from switching loom larger than the advantages or gains. Third, CMs might believe that defaults signal an implicit recommendation or suggestion by a CA (52). Relatedly, default options may affect the meaning CMs assign to actions (36) or may be perceived by CMs as a social norm (7), both of which can affect how CMs value default options relative to nondefault options. Thus, in a final study, we investigate CAs' beliefs about the default effect overall and about each of these three mechanisms in two different types of default games: a version of the original "stay-or-switch" default game from studies 1 and 2, in which CMs initially start with one option and then decide whether to stay or switch (53), and a new "preselect" default game, in which one option is initially preselected/prechecked before CMs make a choice (1).

Materials and Methods. CAs were randomly assigned to play one of two default games, both in a medical decision-making context. The first default game was a stay-or-switch default game, identical to the default game in study $1 \mathrm{j}$. CAs decided whether to tell CMs to imagine they were already taking a medication that was less expensive or a medication that had to be taken less frequently. CMs could either stay with their current medication or switch to the other medication. The second default game was a preselect default game, and was newly designed for study 3. CAs were told that CMs would indicate which medication they would take by clicking a radio button. CAs then decided which medication option to initially preselect or precheck on the CM's decision screen (see Supporting Information for full instructions).

Additionally, to recover CA beliefs about the default effect, we elicited predictions from CAs about CM behavior under different defaults. Specifically, we asked CAs to predict what percentage of CMs would choose each option when it was and was not the default. The difference between these two predictions reveals CAs' beliefs about the effect of setting a default. Using analogous methods, we also recovered CA beliefs related to the three specific mechanisms commonly discussed in analyses of default effects: effort costs, loss aversion, and implicit recommendations. We did so by asking CAs to make predictions about (respectively) CMs who were more lazy than most people, CMs who cared more about the medications' drawbacks than most people, and CMs who were more influenced by their doctors' recommendations than most people. We counterbalanced whether CAs first played the default game or first made predictions about $\mathrm{CM}$ behavior.

\section{Results.}

CA beliefs about the default effect. Overall, only $39.6 \%$ of CAs had directionally correct beliefs about the default effect (i.e., predicted that more CMs would choose an option if it was the default), which was the minority of CAs by a significant margin $\left[\chi^{2}(1)=25.58, p<0.001\right]$. Thus, CAs often demonstrated default neglect not only in their decisions about how to use defaults but also in their understanding of what defaults do. Fig. 3 breaks down CAs' beliefs by the type of default game they played. Among CAs who played the stay-or-switch default game, $43.2 \%$ had directionally correct beliefs about the default effect. Among CAs who played the preselect default game, $36.3 \%$ had directionally correct beliefs about the default effect. These patterns are inconsistent with hypothesis 2. CAs who played the stay-or-switch default game had marginally more correct beliefs than CAs who played the preselect default game $\left[\chi^{2}(1)=2.71, p,=0.099\right]$.
CA strategies in the default games. In the stay-or-switch default game, CAs presented the optimal default $46.9 \%$ of the time, which was not significantly different from chance $\left[\chi^{2}(1)=0.99, p=0.32\right]$. This is consistent with results from studies 1 and 2. However, in the preselect default game, CAs presented the optimal default $79.0 \%$ of the time, which was significantly better than chance $\left[\chi^{2}(1)=102.54, p<0.001\right]$ and significantly better than the behavior of CAs who played the stayor-switch default game $(z=7.93, p<0.001)$. These patterns provide mixed support for hypothesis 1 .

Relationship between CA strategies and CA beliefs. Overall, there was a small but significant positive correlation between whether CAs demonstrated correct beliefs and whether they presented the optimal default $(r=0.10, p=0.01)$. Among CAs who played the stay-or-switch default game, this correlation was significant $(r=0.18, p=0.002)$. However, among CAs who played the preselect default game, this correlation was not significant $(r=0.08, p=0.19)$. These patterns provide mixed support for hypothesis 3 .

CA beliefs about mechanisms driving the default effect. Next, we analyzed CA beliefs related to the three mechanisms-effort costs, loss aversion, and implicit recommendations - that may drive default effects. To do so, we ran an OLS regression predicting CA beliefs about the percentage of CMs who chose a target option using the following predictor variables: a targetoption-is-default dummy variable equal to 1 if CAs were told the target option was the default option; three CM subtype dummy variables equal to 1 if CAs were told that CMs were more influenced by effort costs, loss aversion, or implicit recommendations; and (most importantly) interactions between the target-option-is-default dummy and each of the three CM subtype dummies, using robust standard errors clustered by participant. We found that CAs believed that loss aversion would increase CM selection of the default $(b=0.07, p=0.007)(57)$ However, CAs did not believe that effort costs $(b=0.03$, $p=0.18)$ or implicit recommendations $(b=-0.01, p=0.68)$ would increase CM selection of the default.

Considering each default game separately, in the stay-or-switch default game, CAs believed that loss aversion $(b=0.15, p<$ $0.001)$ and effort costs $(b=0.12, p<0.001)$, but not implicit recommendations $(b=-0.04, p=0.23)$, would increase CM selection of the default. In the preselect default game, CAs did not

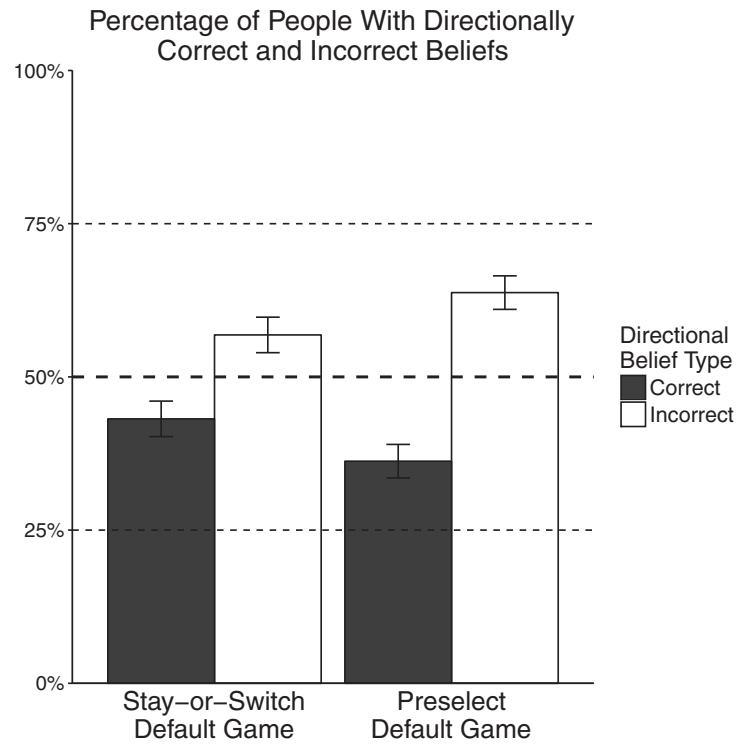

Fig. 3. Study 3: percentage of CAs revealing directionally correct beliefs and directionally incorrect beliefs about the effect of defaults on CM behavior in the stay-or-switch default game and the preselect default game. Error bars are SEs. 
believe that loss aversion $(b=-0.003, p=0.93)$, effort costs $(b=-0.05, p=0.16)$, or implicit recommendations $(b=0.02$, $p=0.47$ ) would increase CM selection of the default.

Discussion. Overall, CAs in study 3 demonstrated only a partial ability to understand and use the default effect, exhibiting support for only one of the three hypotheses in each type of default game.

In the stay-or-switch default game, CAs used optimal defaults at a rate no better than random chance (inconsistent with hypothesis 1), and their beliefs about the direction of the default effect were no more likely than random chance to be correct (inconsistent with hypothesis 2 ). However, CAs were more likely to use optimal strategies if they had correct beliefs (consistent with hypothesis 3 ). In other words, while some "above-average" CAs were good at both understanding and using default effects (which may help explain why at least some firms and marketers do seem to systematically use defaults), the majority of CAs were bad at both understanding and using defaults. CAs, however, did seem to at least partially anticipate two of the three mechanisms (loss aversion and effort costs in the stay-or-switch game, but not implicit recommendations) thought to drive the default effect.

By contrast, in the preselect default game, CAs used optimal defaults at a rate much better than random chance (consistent with hypothesis 1). However, CA beliefs about the direction of the default effect were again no more likely than random chance to be correct (inconsistent with hypothesis 2). CAs also were no more likely to use optimal strategies if they had correct beliefs (inconsistent with hypothesis 3 ). Furthermore, CAs did not seem to anticipate any of the three mechanisms thought to drive the default effect.

Thus, choices in the preselect default game were inconsistent with the notion that CAs made their decisions about which default to set by deliberatively considering their beliefs about what preselect defaults are likely to do. This suggests one of two alternative possibilities. First, it is possible that CAs used a deliberative decision process to select the optimal default in the preselect default game, but that this process was guided by other deliberations that we did not measure rather than by beliefs about the default effect. Second, it is possible that CAs used an intuitive decision process to select the optimal default in the preselect default game, as intuitive decision processes need not consider one's beliefs at all $(15,58,59)$. This would be consistent with previous research that has demonstrated cases in which people engage in optimal decision making without being able to articulate the reasons why $(60,61)$. Additional evidence for this possibility comes from examining the strategies of the $38.8 \%$ of CAs who believed that the effect of setting an option as the default was exactly zero. As one might expect, when these CAs played the stay-or-switch default game, they set optimal defaults at a rate consistent with random chance $[43 \%$ chose the optimal default; $\left.\chi^{2}(1)=1.80, p=0.18\right]$. However, when these CAs played the preselect default game, a significant majority of them $\left[78 \% ; \chi^{2}(1)=41.55, p<0.001\right]$ chose the optimal default (see Supporting Information for further analyses).

Nevertheless, regardless of the nature of the CA decision process, the results of study 3 demonstrate that CA beliefs about the default effect are far from accurate, regardless of which default game is considered.

\section{General Discussion}

Defaults can influence whether people have enough money for retirement, whether people make environmentally friendly decisions, and even whether people live or die. Yet we find that people acting as CAs frequently fail to understand and/or use defaults strategically when trying to influence others' choices, even when doing so is in their best interest. In study 1 , in contrast to both theoretical and expert predictions, we found that only $50.8 \%$ of people set the target option as the default, across 11 samples totaling 2,844 participants. In study 2 , we found that this default neglect in CA decisions persisted even when people were given multiple opportunities for experience and feedback.
In study 3, most CAs revealed incorrect beliefs about how setting a default is likely to affect a CM. Even in cases where CAs were good at systematically using defaults (i.e., in the preselect default game), these decisions did not comport at all with CAs' beliefs. This suggests the possibility that CAs may be intuitively selecting a good nudge strategy rather than choosing one deliberatively (15). A natural question that arises, then, is why CAs were so much better at the preselect default game than the stay-or-switch default game. We speculate that one reason could be that the default option in the preselect default game (a preselected radio button) was more visually prominent than the default option in the stay-or-switch default game (a verbally described "stay" action), relative to their respective nondefault options. People allocate attention to more unique or visually prominent stimuli $(62,63)$, which can affect the decisions they make (64). CAs looking to influence CMs toward a specific target option might thus have allocated greater attention to the choice set in which the target option was more prominent (i.e., was already preselected), leading them to select that choice set with a higher probability. Future research might examine whether a repeated one-shot version of the preselect default game could show improvement by CAs, given CAs' naturally high rate of default utilization in the one-shot preselect default game.

Future work should also explore ways to improve CA decisions. One approach might be to highlight the mechanisms underlying the default effect that CAs naturally seem to anticipate - effort costs and loss aversion-as part of a training intervention to help CAs better notice opportunities for using defaults to influence others $(65,66)$.

Default neglect in CA strategies and beliefs represents a striking failure to use and understand a simple and powerful social influence tactic; it therefore challenges current economic models and related perspectives in psychology, which argue that people should recognize how to use common biases in other people's decision making to influence their choices. Our findings suggest that behavioral theories should begin to consider potential flaws in the decision processes of people who are using influence tactics, not only potential flaws in the decision processes of people who are the target of influence tactics.

Default neglect is also surprising from a policy viewpoint, given the widespread and increasing popularity of using nudges to change behavior in academic and popular media $(8,15)$. Moreover, the startling lack of belief in the power of the default effect among many participants suggests that average CAs, including those who will help to devise and implement public policy, will overlook many opportunities to use defaults to influence people in beneficial directions. Although some organizations and think tanks exist with the express purpose of helping to design better choice architecture (e.g., the Behavioral Insights Team in the United Kingdom), these groups are few and far between, and it would be unreasonable to expect the enormous number of realworld CAs to consult with them on every decision made. In addition, the fact that many CAs do not even believe that the default effect exists makes it less likely that they would seek out help in their decisions about how to use available tactics.

One interesting aspect of our findings is that certain populations (e.g., the "professional samples" in study 1), although still far from achieving optimality, made significantly better CA decisions than others. This suggests a few potential boundary conditions for default neglect. For example, some fields might attract people who already possess above-average critical thinking or perspective-taking abilities that could translate into better CA judgments and decisions (67).

Alternatively, long-term incentive structures in certain fields might motivate people to invest in their own knowledge about how to effectively use choice architecture and social influence tactics $(8,23)$. This may help explain why marketing professionals (who are incentivized to influence people toward specific target options) seem to use defaults more than bureaucrats who help develop public policy (who may simply want to give people options that are easy to understand or widely beneficial, 
without necessarily wanting to influence them toward a specific target option) $(68,69)$.

Overall, our research highlights the fact that the potential scope for improving social welfare via behavioral policy

1. Johnson EJ, Goldstein D (2003) Do defaults save lives? Science 302:1338-1339.

2. Bernheim BD, Forni L, Gokhale J, Kotlikoff LJ (2000) How much should Americans be saving for retirement? Am Econ Rev 90:288-292.

3. Kirkham E (2016) 1 in 3 Americans has saved $\$ 0$ for retirement. Time.com Money. Available at time.com/money/4258451/retirement-savings-survey/. Accessed July 19 , 2017.

4. Madrian BC, Shea DF (2001) The power of suggestion: Inertia in 401(k) participation and savings behavior. $Q J$ Econ 116:1149-1187.

5. Tavoni A, Dannenberg A, Kallis G, Löschel A (2011) Inequality, communication, and the avoidance of disastrous climate change in a public goods game. Proc Natl Acad Sci USA 108:11825-11829.

6. Sunstein CR, Reisch L (2014) Automatically green: Behavioral economics and environmental protection. Harv Environ Law Rev 38:127-158.

7. Loewenstein G, Bryce C, Hagmann D, Rajpal S (2015) Warning: You are about to be nudged. Behav Sci Pol 1:35-42.

8. Thaler RH, Sunstein CR (2008) Nudge: Improving Decisions About Health, Wealth, and Happiness (Penguin, New York).

9. Samuelson W, Zeckhauser R (1988) Status quo bias in decision making. J Risk Uncertain 1:7-59.

10. Steffel M, Williams EF, Pogacar R (2016) Ethically deployed defaults: Transparency and consumer protection via disclosure and preference articulation. J Mark Res 53: $865-880$.

11. Suri G, Sheppes G, Schwartz C, Gross JJ (2013) Patient inertia and the status quo bias: When an inferior option is preferred. Psychol Sci 24:1763-1769.

12. Allcott $H$, Mullainathan $S$ (2010) Behavior and energy policy. Science 327:1204-1205.

13. Larrick RP, Soll JB (2008) The MPG illusion. Science 320:1593-1594.

14. Johnson EJ, et al. (2012) Beyond nudges: Tools of a choice architecture. Market Lett 23:487-504

15. Kahneman D (2011) Thinking, Fast and Slow (Farrar Straus Giroux, New York).

16. Madrian BC (2014) Applying insights from behavioral economics to policy design. Annu Rev Econ 6:663-688.

17. Milkman KL, Chugh D, Bazerman MH (2009) How can decision making be improved? Perspect Psychol Sci 4:379-383.

18. Soll JB, Milkman KL, Payne JW (2014) A User's Guide to Debiasing, Handbook of Judg ment and Decision Making, eds Keren G, Wu G (Wiley-Blackwell, Chichester, UK), Vol 33.

19. Montoy JCC, Dow WH, Kaplan BC (2016) Patient choice in opt-in, active choice, and opt-out HIV screening: Randomized clinical trial. BMJ 532:h6895.

20. Centers for Disease Control and Prevention (2017) HIV in the United States: At a glance. Available at https://www.cdc.gov/hiv/statistics/overview/ataglance.html. Accessed July 19, 2017.

21. Dovidio JF, Fiske ST (2012) Under the radar: How unexamined biases in decisionmaking processes in clinical interactions can contribute to health care disparities. Am J Epidemiol 102:945-952.

22. Hovland $\mathrm{Cl}$, Janis IL, Kelly HH (1953) Communication and persuasion: Psychologica studies of opinion change. Am Sociol Rev 19:315.

23. Cialdini RB (1984) Influence: The Psychology of Persuasion (Harper Business, New York)

24. Cialdini RB, Goldstein NJ (2004) Social influence: Compliance and conformity. Annu Rev Psychol 55:591-621.

25. Petty RE, Cacioppo JT (1986) The elaboration likelihood model of persuasion. Adv Exp Soc Psychol 19:123-205.

26. Wood W (2000) Attitude change: Persuasion and social influence. Annu Rev Psychol 51:539-570.

27. Freedman J, Fraser SC (1966) Compliance without pressure: The foot-in-the-door technique. J Personal Soc Psychol 4:195-202.

28. Gouldner A (1960) The norm of reciprocity: A preliminary statement. Am Sociological Rev 25:161-178.

29. Malhotra D, Bazerman MH (2008) Psychological influence in negotiation: An introduction long overdue. J Manage 34:509-531.

30. McGinn KL, Milkman KL, Nöth M (2012) Walking the talk in multiparty bargaining An experimental investigation. J Econ Psychol 33:278-291.

31. Camerer CF (2003) Behavioral Game Theory: Experiments in Strategic Interaction (Princeton Univ Press, Princeton).

32. Chong D, Druckman JN (2007) Framing theory. Annu Rev Polit Sci 10:103-126.

33. Crawford VP (1990) Explicit communication and bargaining outcomes. Am Econ Rev 80:213-219.

34. DellaVigna S (2009) Psychology and economics: Evidence from the field. J Econ Lit 47:315-372.

35. Pronin E, Lin DY, Ross L (2002) The bias blind spot: Perceptions of bias in self versus others. Personal Soc Psychol Bull 28:369-381.

36. Davidai S, Gilovich T, Ross LD (2012) The meaning of default options for potential organ donors. Proc Natl Acad Sci USA 109:15201-15205.

37. Van Boven L, Dunning D, Loewenstein G (2000) Egocentric empathy gaps between owners and buyers: Misperceptions of the endowment effect. J Personal Soc Psychol 79:66-76. interventions-especially those that people fail to naturally use as social influence tactics-is vast. At the same time, however it seems unlikely that this tremendous potential will be realized without external assistance.

38. Fox CR, Rottenstreich Y (2003) Partition priming in judgment under uncertainty. Psychol Sci 14:195-200.

39. Van den Steen E (2011) Overconfidence by Bayesian-rational agents. Manage Sci 57:884-896.

40. Heath C (1999) On the social psychology of agency relationships: Lay theories of motivation overemphasize extrinsic incentives. Organ Behav Hum Decis Process 78 $25-62$.

41. Kagel JH, Levin D (1986) The winner's curse and public information in common value auctions. Am Econ Rev 76:894-920.

42. Tversky A, Kahneman D (1986) Rational choice and the framing of decisions. J Business 59:S251.

43. Ball SB, Bazerman MH, Carroll JS (1991) An evaluation of learning in the bilateral winner's curse. Organ Behav Hum Decis Process 48:1-22.

44. Selten R, Abbink K, Cox R (2005) Learning direction theory and the winner's curse. Exp Econ 20:5-20.

45. Brehmer B (1980) In one word: Not from experience. Acta Psychol 45:223-241.

46. Neale MA, Bazerman MH (1991) Cognition and Rationality in Negotiation. (Free Press, New York).

47. Sloman SA, Hagmayer Y (2006) The causal psycho-logic of choice. Trends Cogn Sci 10:407-412.

48. Johnson EJ, Goldstein DG (2013) Decisions by default. The Behavioral Foundations of Public Policy, ed Shafir E (Princeton Univ Press, Princeton), pp 417-427.

49. Blount $S$, Larrick RP (2000) Framing the game: Examining frame choice in bargaining Organ Behav Hum Decis Process 81:43-71.

50. Gneezy U, Rustichini A (2000) Pay enough or don't pay at all. $Q J$ Econ 115:791-810.

51. Rogers T, Milkman KL (2016) Reminders through association. Psychol Sci 27: 973-986.

52. McKenzie CR, Liersch MJ, Finkelstein SR (2006) Recommendations implicit in policy defaults. Psychol Sci 17:414-420.

53. Brenner L, Rottenstreich Y, Sood S, Bilgin B (2007) On the psychology of loss aversion: Possession, valence, and reversals of the endowment effect. $J$ Consumer Res 34 369-376.

54. Andreoni J, Croson R (2008) Partners versus strangers: Random rematching in public goods experiments. Handbook of Experimental Economic Results, eds Plott CR, Smith VL (Elsevier, New York), Ed 1, Vol 1, pp. 776-783.

55. Baron J, Ritov I (1994) Reference points and omission bias. Organ Behav Hum Decis Process 59:475-498.

56. Kahneman D, Knetsch JL, Thaler RH (1991) Anomalies: The endowment effect, loss aversion, and status quo bias. J Econ Perspect 5:193-206.

57. Imas A, Sadoff S, Samek A (2017) Do people anticipate loss aversion? Manage Sci 63:1271-1284

58. Loewenstein GF, Weber EU, Hsee CK, Welch N (2001) Risk as feelings. Psychol Bull 127:267-286.

59. Suter RS, Pachur T, Hertwig R (2016) How affect shapes risky choice: Distorted probability weighting versus probability neglect. J Behav Decis Making 29: 437-449.

60. Klein G (2008) Naturalistic decision making. Hum Factors 50:456-460.

61. Neale MA, Northcraft GB (1990) Experience, expertise, and decision bias in negotiation: The role of strategic conceptualization. Research in Bargaining and Negotiating in Organizations, eds Sheppard B, Bazerman M, Lewicki R (JAI Press, Greenwich, CT), Vol 2, pp 55-75.

62. Taylor SE, Fiske ST (1978) Salience, attention, and attribution: Top of the head phenomena. Adv Exp Soc Psychol 11:249-288.

63. Treisman A, Gormican S (1988) Feature analysis in early vision: Evidence from search asymmetries. Psychol Rev 95:15-48.

64. Halevy N, Chou EY (2014) How decisions happen: Focal points and blind spots in interdependent decision making. J Personal Soc Psychol 106:398-417.

65. Bazerman MH, Chugh D (2005) Bounded awareness: Focusing failures. Negotiation in Frontiers of Social Psychology: Negotiation, ed Thompson LL (Psychol Press, College Park, MD), pp 7-26.

66. Morewedge CK, et al. (2015) Debiasing decisions: Improved decision making with a single training intervention. Pol Insights Behav Brain Sci 2:129-140.

67. West RF, Toplak ME, Stanovich KE (2008) Heuristics and biases as measures of critical thinking: Associations with cognitive ability and thinking dispositions. J Educ Psychol 100:930-941.

68. Lohr S (October 15, 2011) The default choice, so hard to resist. NY Times. Available at www.nytimes.com/2011/10/16/technology/default-choices-are-hard-to-resistonline-or-not.html. Accessed July 19, 2017.

69. Sunstein CR (2013) Simpler: The Future of Government (Simon \& Schuster, New York).

70. Daniels DP, Zlatev JJ (2017) Choice architects reveal a bias toward positivity and certainty. SSRN. Available at https://ssrn.com/abstract=2832703. Accessed July 19 2017.

71. Becker GM, DeGroot MH, Marschak J (1964) Measuring utility by a single-response sequential method. Behav Sci 9:226-232.

72. Johnson EJ, Hershey J, Meszaros J, Kunreuther H (1993) Framing, probability distortions, and insurance decisions. J Risk Uncertainty 7:35-51. 